\title{
Comparison of natriuretic, uricosuric, and antihypertensive properties of tienilic acid, bendrofluazide, and spironolactone
}

\author{
C J C ROBERTS, A J MARSHALL，SUSAN HEATON， D W BARRITT
}

British Medical fournal, 1979, 1, 224-226

\section{Summary and conclusions}

The antihypertensive properties of the new diuretic tienilic acid were investigated. Thirteen previously untreated hypertensive patients took part in a double-blind crossover study in which 30 days' treatment with tienilic acid $250 \mathrm{mg}$, bendrofluazide $5 \mathrm{mg}$, and spironolactone $100 \mathrm{mg}$ were compared. Bendrofluazide caused the greatest natriuresis on the first treatment day and the most rapid fall in blood pressure. The ultimate antihypertensive effect of all three drugs was similar. Tienilic acid caused a noticeable reduction in serum urate concentrations and a rise in urate clearance, in contrast to the other two agents, which caused slight urate retention. Tienilic acid and bendrofluazide caused falls and spironolactone a rise in plasma potassium concentrations. No untoward effects were seen from any of the drugs.

It is concluded that tienilic acid is a moderately potent diuretic that lowers plasma urate concentrations. It may be the drug of first choice for hypertensive patients who already have gout or are likely to develop it when taking thiazide diuretics.

\section{Introduction}

Diuretics are accepted as initial treatment for many patients with hypertension. A common adverse effect, however, is raised blood urate concentrations, and gout is occasionally precipitated. ${ }^{1}$ All the commonly available diuretic drugs cause rises in serum urate concentrations by altering renal urate handling secondary to extracellular fluid volume contraction. ${ }^{2}$ Hyperuricaemia has been implicated as a possible factor in the development of atheroma, ${ }^{3}$ but its importance as an independent risk factor for coronary artery disease is disputed. ${ }^{*}$ Tienilic acid (2, 3-dichloro-4-(2-thienylcarbonyl)-phenoxyacetic acid) is a new diuretic that enhances urate excretion and causes a reduction in serum urate concentration. ${ }^{5}$ Its natriuretic action is due to inhibition of sodium reabsorption in the cortical diluting segment of the nephron, ${ }^{6}$ and its duration of action is four to eight hours. ${ }^{7}$

The exact mechanism by which diuretics produce their antihypertensive effect is not known. Although the effect is thought to be related to their natriuretic action, ${ }^{8}$ diuretic potency does not parallel antihypertensive potency. The aims of the present study were, firstly, to investigate the properties of tienilic acid in the treatment of hypertension and, secondly, to examine the influence of diuretic potency on the antihypertensive response. We therefore compared tienilic acid with two drugs of proved

\footnotetext{
University Department of Medicine and Department of Cardiology, Bristol Royal Infirmary, Bristol BS2 8HW

C J C ROBERTS, MB, MRCP, lecturer in clinical pharmacology

A J MARSHALL, MD, MRCP, tutor and senior medical registrar

SUSAN HEATON, MB, BS, clinical assistant

D W BARRITT, MD, FRCP, lecturer and consultant physician
}

efficacy in hypertension but with widely differing diuretic potency and action. The time course of the effect, the pattern and characteristics of the diuretic responses, and the effects on potassium and uric acid handling were assessed.

\section{Patients and methods}

The patients had previously untreated essential hypertension, with systolic blood pressures above $150 \mathrm{~mm} \mathrm{Hg}$ and diastolic blood pressures above $95 \mathrm{~mm} \mathrm{Hg}$ (phase $\mathrm{V}$ ) throughout the initial period of assessment. Patients were excluded from the trial if they had accelerated hypertension, hypokalaemia, diabetes, gout, or other complications likely to influence the results of the study.

The trial was a double-blind cross-over study comparing three treatments, using a Latin square design. The treatments were tienilic acid $250 \mathrm{mg}$, spironolactone $100 \mathrm{mg}$, and bendrofluazide $5 \mathrm{mg}$ administered by mouth daily at $8 \mathrm{am}$. A triple dummy technique was used so that the commercially available formulations of spironolactone and bendrofluazide were administered. Throughout the study patients took three tablets every morning. Each patient's tablets were prepacked in calendar packs so that active treatments were started on the appropriate days in the trial protocol. After the initial attendance there was a 40-day run-in period when patients received placebo tablets only. This was followed by the three treatment periods of 30 days each separated by two washout periods of 26 days each. Patients attended the hypertension clinic at fortnightly intervals. Treatment periods began on the day before a clinic visit, and thus blood pressure could be measured 24 hours after the start of treatment. At each clinic visit blood pressure was recorded using a London School of Hygiene and Tropical Medicine sphygmomanometer three times: after five minutes' rest supine, after one minute standing, and after one minute of two-step exercise. Clinical examination was performed and a standard questionnaire of symptoms administered. On the day before each clinic visit patients collected urine from 8 am to $4 \mathrm{pm}$ (eight hours) and, separately, from $4 \mathrm{pm}$ to 8 am the following morning (eight- to 24-hour collection). Urine volumes and sodium, potassium, and urate concentrations were measured in all collections using automated methods. During the trial patients ate their normal diets but were asked to restrict alcohol intake on the days of urine collection. No supplementary potassium was given. The results of biochemical and haematological investigations were monitored by a physician who did not meet the patients.

Analysis - Analysis of variance was used to assess statistical significance. Results were judged as significant at a probability value of $P<0.05$ and as highly significant at $P<0.001$. Mean blood pressure (BP) was calculated as $\frac{1}{3}$ (systolic $\mathrm{BP}+(2 \times$ diastolic $\left.\mathrm{BP})\right)$.

\section{Results}

Thirteen patients completed the study with full data collection and were used for analysis. Their ages ranged from 32 to 73 years, and nine were men. Three further patients were unable to comply with the trial protocol, and one was withdrawn during the run-in period as his hypertension was judged to be too severe for the trial drug regimen.

Changes in blood pressure-Each drug caused significant falls in both systolic and diastolic blood pressures when measured supine, standing, and after exercise. The time course of the response was similar in each of the three positions. Figure 1 shows the changes in standing mean blood pressure. The ultimate blood pressures for each drug were closely similar. The onset of the antihypertensive effect of bendrofluazide occurred within the first day of treatment. Appreciable antihypertensive effects of spironolactone and tienilic acid were not in evidence until the second measurement (two weeks after starting treatment). 




FIG $1-$ Mean ( \pm SE of mean) standing blood pressures in 13 hypertensive patients given three diuretics in random order. Values on day $\mathrm{C}$ are those recorded during placebo treatment before next appropriate drug started. Values on days 1,15 , and 29 are those recorded immediately after 1 st, 15 th, and 29 th treatment days.

Urine volume and sodium excretion-Figure 2 shows sodium excretion. Changes in urine volume in response to the diuretics paralleled the changes in sodium excretion. The patterns of the natriuretic response to the diuretics were different $(P<0.001)$. Sodium excretion increased significantly above control values in the eight hours after the first administration of all three diuretics. This increase was greatest with bendrofluazide $(P<0.02)$. With bendrofluazide and spironolactone sodium excretion in the first 16-hour collections was also significantly raised, and 24 -hour sodium excretion was high. Tienilic acid caused an increased sodium excretion in the first eight hours, but

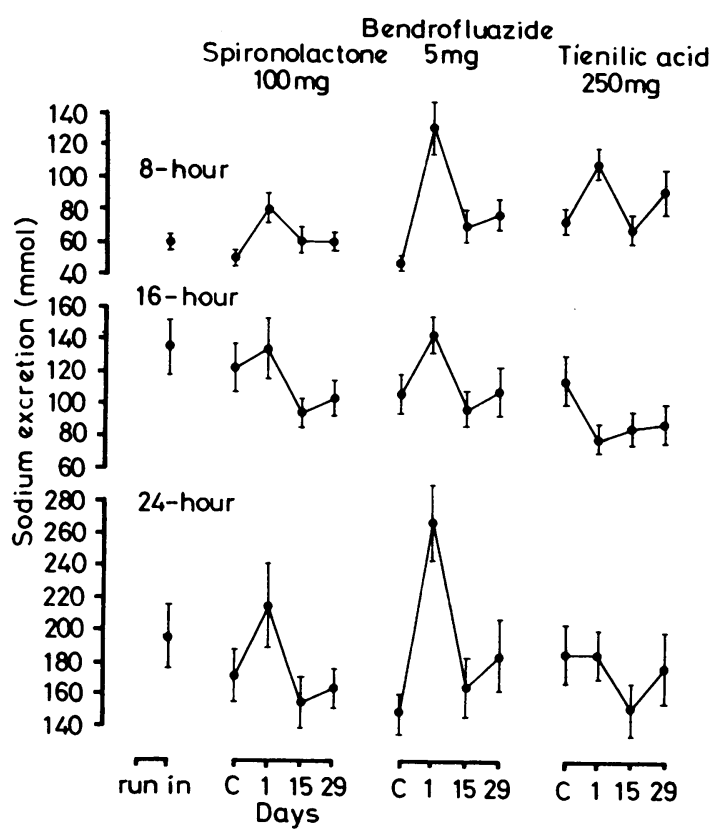

FIG 2-Mean ( \pm SE of mean) sodium excretion in 13 hypertensive patients given diuretics in random order. Top graph show output during eight-hour period after administration of drug; middle graphs show output during next 16 hours; bottom graphs show total output over 24 hours. Values on day $C$ are those obtained from urine collection before next drug started. Values on days 1, 15, and 29 are those obtained from urine collections made on those treatment days.

Conversion: SI to traditional units-Sodium: $1 \mathrm{mmol}=$ $1 \mathrm{mEq}$. during the subsequent 16 hours sodium excretion was significantly reduced, so that the total 24 -hour output was not above control values. Subsequently the sodium excretion with all the diuretics was modified. Sodium excretion in the eight-hour collections was slightly above that on control days. In the 16-hour collections the sodium output was reduced in comparison to control values with all three diuretics. Twenty-four-hour sodium output was similar to that on control days.

Potassium excretion-Potassium excretion increased significantly above control values in the eight hours after the first administrations of bendrofluazide and tienilic acid. Twenty-four-hour excretion of potassium was little affected by either diuretic. On subsequent days the pattern of potassium excretion was similar to control values. Mean urinary potassium was slightly but not significantly reduced on the first day of administration of spironolactone. Subsequently potassium excretion returned to control values.

Plasma potassium concentrations-The differences between the drugs in respect of plasma potassium concentrations were highly significant. Spironolactone caused a rise in concentration from $3.8 \pm 0.05$ to $4.1 \pm 0.1 \mathrm{mmol}(\mathrm{mEq}) / 1(\mathrm{P}<0.01)$, while bendrofluazide caused a fall from $3.7 \pm 0.07$ to $3.5 \pm 0.1 \mathrm{mmol}(\mathrm{mEq}) / 1(P<0.02)$ and tienilic acid a fall from $3.8+0.08$ to $3.5+0.09 \mathrm{mmol}(\mathrm{mEq}) / \mathrm{l}(\mathrm{P}<0.02)$.

Plasma urate concentrations-Spironolactone and bendrofluazide caused significant increases in plasma urate concentration above control values, the increase being greater with bendrofluazide. With tienilic acid there was a $50 \%$ reduction in plasma urate concentrations, which was complete 24 hours after the first administration and maintained during the rest of the treatment period $(\mathbf{P}<0.001$; see fig 3$)$.

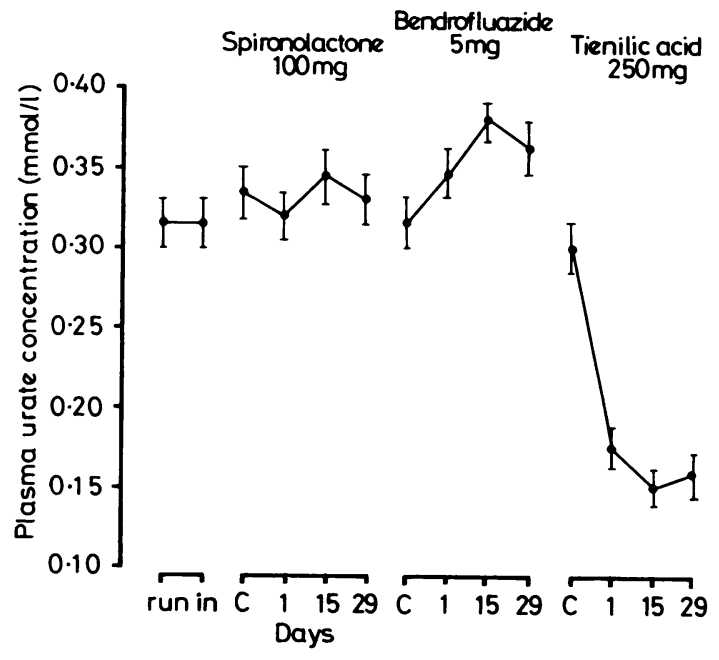

FIG 3-Mean ( \pm SE of mean) plasma urate concentrations in 13 hypertensive patients given diuretics in random order. Values on day $\mathbf{C}$ are those recorded during placebo treatment before next drug started. Values on days 1,15 , and 29 are those obtained immediately after these treatment days.

Conversion: SI to traditional units-Plasma urate: 1 $\mathrm{mmol} / 1 \approx 16.8 \mathrm{mg} / 100 \mathrm{ml}$

Excretion of uric acid-The pattern of uric acid excretion differed between the three drugs $(P<0.001)$. Tienilic acid caused a pronounced rise in excretion in the eight hours after administration $(P<0.02)$, and the total 24-hour output on the first day of administration was above the control value (not significant). Spironolactone caused a slight rise in uric acid excretion in the eight hours after the first administration $(P<0.05)$ but no increase in 24-hour output. Bendrofluazide had no detectable effect on total excretion.

Urate clearance-Highly significant differences in urate clearance were found between the drugs. Spironolactone and bendrofluazide caused reductions in urate clearance during the treatment periods $(P<0.01$ and $P<0.05$ respectively), while tienilic caused an increase $(\mathrm{P}<0.001)$.

Body weight-About $1 \mathrm{~kg}$ body weight was lost with each diuretic, there being no difference between the treatments in this respect.

Adverse effects-Slight increases in haemoglobin and blood urea concentrations occurred with all three diuretics. No change in random blood glucose concentrations occurred, and no haematological or biochemical abnormalities were seen. 


\section{Discussion}

Study design-We found that this new clinical-trial design was ideal for the objectives of the study. The use of calendar packs allowed treatment periods to be started on the day before clinic visits so that urine collections could be made on the first day of treatment and blood pressures recorded 24 hours after the start. The design is particularly suitable for simultaneous comparisons of the changes in natriuresis and blood pressure due to diuretic drugs. To maintain double-blind trial conditions it was important to have an independent trial co-ordinator monitoring biochemical results, as it would have been easy for the trial physician to recognise tienilic acid treatment by the fall in plasma urate concentration.

Antihypertensive and natriuretic effects-Examination of the sodium excretion on the first day of tienilic acid administration confirmed that the drug is a diuretic with a duration of action of under eight hours. The study also confirmed reports of its antihypertensive action. ${ }^{9}$ The ultimate falls in blood pressure achieved with tienilic acid, spironolactone, and bendrofluazide were similar. The onset of the effect was more rapid with bendrofluazide. There was clear evidence that all three agents caused natriuresis at the start of treatment, but the sodium excretion produced by bendrofluazide far outweighed that by the other two agents. This suggests that the natriuretic potency of diuretic drugs governs the rapidity of their antihypertensive effect. While differences between the drugs in natriuresis were seen on the first day of treatment, on subsequent occasions sodium excretion with all three drugs was similar to that on control days. The degree of weight loss was the same with each drug. Thus there was evidence that homeostatic sodiumconserving mechanisms were operating to limit the diuresis. These mechanisms account for the fact that similar degrees of extracellular fluid volume depletion may be achieved in hypertensive patients with diuretics of differing potencies. ${ }^{10}$ As antihypertensive action relates to volume contraction, ${ }^{11}$ the similarity in ultimate blood pressure with the three drugs in this trial can also be explained.

Plasma potassium concentration-The effects of the three drugs on plasma potassium concentrations were as expected from their sites of action in the nephron. The fall in concentration due to tienilic acid was similar to that caused by bendrofluazide, and so tienilic acid would appear to have no advantage in this respect.

Plasma urate concentration and urate clearance-The drugs had noticeably different effects on urate handling. There was evidence of urate retention after treatment with both spironolactone and bendrofluazide. Two mechanisms for diureticinduced urate retention are postulated. It has been suggested that diuretic drugs and uric acid might compete for active tubular secretion. Alternatively, there is evidence that urate retention relates more directly to changes in urate clearance secondary to extracellular fluid volume contraction. ${ }^{12}$ Two observations in this study support the latter theory. Firstly, spironolactone has a steroidal structure and is metabolised in the liver. It would be unlikely to compete with uric acid for secretion. Secondly, output of uric acid was normal or increased in the eight hours after administration of bendrofluazide and spironolactone when competition for tubular secretion would be expected to be occurring. In contrast, tienilic acid caused an increase in urate clearance resulting in an initial rise in uric acid output and a rapid and pronounced fall in plasma urate concentrations. These findings fully support the observations of others that tienilic acid reduces plasma urate concentrations through a renal mechanism. ${ }^{5}$

We conclude that tienilic acid is a moderately potent diuretic with useful antihypertensive properties and that it lowers plasma potassium concentrations. It also lowers plasma urate concentrations and consequently will be useful for those patients who develop gout when receiving thiazide diuretics. It may be the drug of first choice for hypertensive patients who also have gout. Whether tienilic acid is a major therapeutic advance for routine use in hypertension will depend on an assessment of the advantages and disadvantages of prolonged hypouricaemia. Diuretic potency determines the time course of the antihypertensive effect of a drug rather than the ultimate reduction in blood pressure.

We are grateful to Mrs $M$ Hopton for invaluable technical help. We thank Smith, Kline, and French Laboratories Ltd for supplying trial materials.

AJM was supported by a Bristol Health District (Teaching) research grant.

\section{References}

1 Bryant, J M, et al, American fournal of Medicine, 1962, 33, 408.

2 Steele, T H, and Oppenheimer, S, American fournal of Medicine, 1969, 47, 564.

${ }^{3}$ Ferrel, W J, Siegelant, A B, and Johnson, E S, Archives of Internal Medicine, 1962, 33, 408.

${ }^{4}$ Kannel, W B, et al, Annals of Internal Medicine, 1971, 74, 1.

5 Reese, O G, and Steele, T H, American fournal of Medicine, 1976, 60, 973.

6 Stote, R M, et al, Clinical Research, 1974, 22, 721.

Wood, A J, et al, Clinical Pharmacology and Therapeutics, 1978, 23, 697.

Dustan, H R, Tarazi, R C, and Bravo, E L, Archives of Internal Medicine, 1974, 133, 1007. 9 Okun, R, and Beg, M, Clinical Pharmacology and Therapeutics, 1978, 23,

10 Acchiardo, S, Dunstan, H P, and Tarazi, R C, Cleveland Clinic Quarterly, $1972,39,153$.

11 De Carvalho, J G, et al, Clinical Pharmacology and Therapeutics, 1977, 22, 875.

12 Roberts, C J C, et al, British fournal of Clinical Pharmacology, 1978, 6, 129.

(Accepted 15 November 1978)
ONE HUNDRED YEARS AGO A curious commentary on the alleged absence of any sanitary grounds for objection to the existing method of disposal of the dead is furnished by two casual paragraphs which fall under our notice this week. The first comes from Arundel, where, it is reported, a vestry meeting was held, at which the vicar was present, urging upon his Grace the Duke of Norfolk the necessity of procuring a new burial ground in the borough. No one but his Grace is possessed of any land in the vicinity. The second is this. At the present moment the Bridgwater Rural Sanitary Authority is in rather a grave difficulty about the drainage of the parish churchyard of Puriton. The drainage is very bad; that much is admitted. Indeed, it would be very difficult business to throw doubt upon it; for the water from the graveyard percolates into the wells used by the inhabitants for drinking purposes. The difficulty is as to who is to pay for the necessary improvements. The sanitary authority appealed to the justices of the peace; the justices of the peace referred the matter to the vicar and churchwardens; and the vicar and churchwardens sullenly say that, since the abolition of church-rates, they have no funds for such outside work. It probably requires all they can do to see that the vicar's salary is regularly paid. The ratepayers, of course, object to the expense being thrown upon the parish; and so the perplexed clerk to the sanitary board has been requested to institute further inquiries on the subject. Yet something must be done. The inhabitants of Puriton cannot go on drinking water contaminated with washings from a churchyard-unless it is not objected that at no very distant date they may take up their narrow abode there altogether. Moreover, it should be remembered that the dead do not cease from troubling the living when a churchyard is "closed." The recent history of the Aldgate pump is a case in point ; its water, poisoned by churchyard infiltration, was till quite lately the beverage of a population who were tempted by its cooling nitrates and "sparkling" character. Country churchyards are commonly placed on small eminences, and their influence on the drinking-water is a subject which might tempt, but which will certainly not bear, investigation. A spot which is to-day on the outskirts becomes to-morrow the centre of a suburb or village, and it is a very short-sighted sanitation which can assume light-heartedly that the inhumation of the dead-whatever other grounds there may be for approving and retaining it-is a practice which can be sustained on grounds of public health, or that Mr Seymour Haden's device at all meets the difficulty. It no doubt mitigates it where soil is favourable and sites at hand; but that is all that can reasonably be said in favour of it. (British Medical fournal, 1879.) 